\title{
ChemComm
}

Cite this: Chem. Commun., 2014 50,4225

Received 7th December 2013,

Accepted 29th January 2014

DOI: $10.1039 / c 3 c c 49307 e$

www.rsc.org/chemcomm

\section{MOF membrane synthesis in the confined space of a vertically aligned LDH network $\dagger$}

\author{
Yi Liu, * Nanyi Wang, Lisa Diestel, Frank Steinbach and Jürgen Caro*
}

MOF membranes have gained widespread attention due to their unprecedented gas separation performance. Relying on physical interactions, we successfully deposited MOF seeds on a substrate modified with a network of vertically aligned LDH walls before secondary growth of the MOF layer. ZIF-8 membranes thus prepared show considerable $\mathrm{H}_{2}$ permeance with high $\mathrm{H}_{2}-\mathrm{CH}_{4}$ selectivity. This approach is in general suitable for the deposition of nanoparticles on solid surface and their subsequent growth into a dense layer.

Metal-organic frameworks (MOFs), a new class of crystalline porous materials, are composed of metal ions or metal oxide clusters coordinated by organic linkers to form highly regular porous networks. Since pioneering works on MOFs (also called coordination polymers) in the $1990 \mathrm{~s},{ }^{1}$ MOFs have had extensive interest due to their unprecedented opportunities for a wide range of applications in gas storage, purification, catalysis and sensing. ${ }^{2}$ In particular, the flexibility of pore size and sorption behaviour make them ideal candidates as membranes for gas separation. ${ }^{3}$

Reports of fabrication of compact MOF membranes first appeared in 2009. ${ }^{4}$ In contrast to the thriving research on MOF materials, only limited progress has been made in the field of MOF membranes, owing to the weak interfacial bonding between MOFs and chemically inert substrates such as porous $\alpha-\mathrm{Al}_{2} \mathrm{O}_{3}$. In general, it is difficult to prepare a compact MOF membrane by a direct in situ growth method since the heterogeneous nucleation density of MOF crystals on ceramics is low. Therefore, modification of the support surface with functional groups like organosilanes, ${ }^{5}$ imidazole ligands, ${ }^{6}$ graphite ${ }^{7}$ and $\mathrm{ZnO}^{8}$ became necessary to improve the nucleation density in the case of direct MOF crystallization. In comparison, secondary growth using seed crystallites offered enormous superiority, such as a reduced dependence on substrate and better control over the microstructure. In order to attach MOF seeds and ensure that they do not easily peel off during secondary growth, polymer binder-assisted

Institute of Physical Chemistry and Electrochemistry, Leibniz University Hannover, Callinstr.3A, D-30167 Hannover, Germany.E-mail: yi.liu@pci.uni-hannover.de, juergen.caro@pci.uni-hannover.de

† Electronic supplementary information (ESI) available. See DOI: 10.1039/ c3cc49307e seeding, ${ }^{9}$ thermal seeding, ${ }^{10}$ reactive seeding and in situ seeding methods ${ }^{11}$ were developed. Very recently, a novel counter-diffusion concept was developed in MOF membrane synthesis. With this method, well-intergrown HKUST- ${ }^{12}$ and ZIF- ${ }^{13}$ membranes were successively prepared. In particular, the prepared ZIF-8 membrane represented a high propane/propene selectivity,${ }^{14}$ showing a bright prospect for applying MOF membranes. Different from the aforementioned methods, here we develop a new route to prepare MOF membranes by the use of physical interactions.

Our concept is shown in Fig. 1. Prior to seeding, the surface of substrate is segmented into micrometer-sized two-dimensional (2D) compartments by vertically aligned layered double hydroxides (LDHs). LDHs, which have the general formula $\left[\mathrm{M}_{1-x}{ }^{2+} \mathrm{M}_{x}^{3+}(\mathrm{OH})_{2}\right]$ $\left[\mathrm{A}^{n-}\right]_{x / n} \cdot z \mathrm{H}_{2} \mathrm{O}\left(\mathrm{M}^{2+}, \mathrm{M}^{3+}\right.$, and $\mathrm{A}^{n-}$ represent di-, tri-valent metal ions and $n$-valent anions, respectively), are representative of layered compounds. LDHs consist of positively charged brucite-like layers and interlayer galleries containing charge compensating anions. LDHs are selected as "walls" between the segments due to their high length-to-

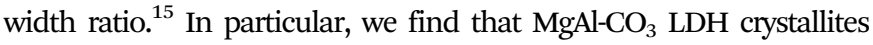
could be easily in situ grown on porous $\alpha-\mathrm{Al}_{2} \mathrm{O}_{3}$ substrate to form $\mathrm{LDH}$ networks with diverse microstructures by proper manipulation of

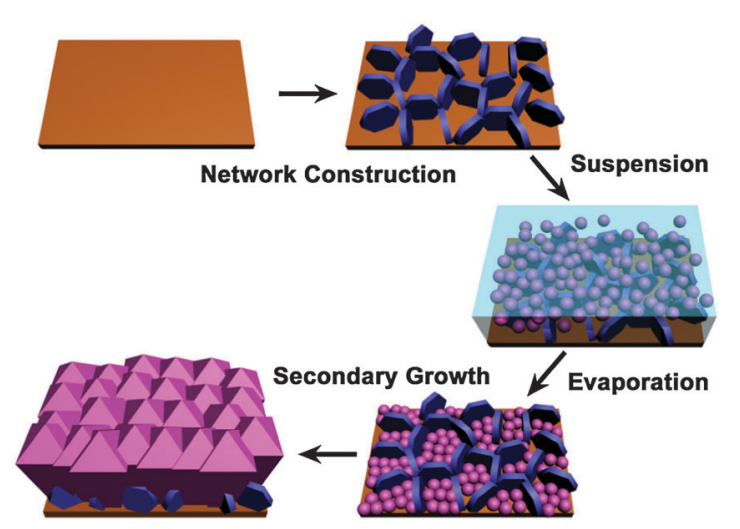

Fig. 1 Schematic illustration of the ZIF-8 membrane synthesis in the confined space of a vertically aligned layered double hydroxide (LDH) network illustrating the role of the LDH network: a "perch" for the seeds. 
synthetic parameters (shown in ESI- $1 \dagger$ ). In the case where $\mathrm{H}_{2} \mathrm{O}$ is used as solvent, a vertically aligned $\mathrm{LDH}$ network with appropriate mutual distances is formed on the $\alpha-\mathrm{Al}_{2} \mathrm{O}_{3}$ substrate (Fig. S1a, ESI $\dagger$ ). Although $\mathrm{LDH}$ networks become more densely packed by surface modification of the substrate with a $\gamma-\mathrm{Al}_{2} \mathrm{O}_{3}$ intermediate layer (Fig. S1b, ESI $\dagger$ ) or the use of methanol solvent instead of $\mathrm{H}_{2} \mathrm{O}$ (Fig. S1c and d, ESI $\dagger$ ), they are not the optimum choice as walls since the mass transfer resistance would also increase. In the next step, ZIF-8 seeds dispersed in methanol suspension are dip-coated onto the surface of $\mathrm{LDH}$ network-modified alumina substrate. After evaporation of the solvent, ZIF-8 seeds are readily embedded into these segments under capillary forces. Owing to the limited space, ZIF-8 seeds trapped in the lattice are spontaneously subject to hindrance from adjacent $\mathrm{LDH}$ walls as well as neighbouring ZIF-8 seeds, which effectively prevent their detachment from the substrate during secondary growth. During secondary growth, ZIF-8 seeds gradually grow bigger, merge with each other and form a compact ZIF-8 layer, in which the LDH network is in turn embedded.

The process of membrane fabrication was characterized by SEM and XRD (experimental details are shown in ESI- $2 \dagger$ ). As shown in Fig. 2a, the in situ grown $\mathrm{LDH}$ walls showed a typical plate-like morphology with mutual distances between them of $\sim 1 \mu \mathrm{m}$. The height of the $\mathrm{LDH}$ network was around $1.7 \mu \mathrm{m}$ (Fig. 2b). The corresponding XRD patterns showed clearly distinguishable diffraction peaks at $2 \theta$ values of $11.6^{\circ}$ and $23.1^{\circ}$ which were coincident with the (003) and (006) crystal planes of the LDH phase (Fig. 3a and b). ${ }^{16}$

Due to severe peak overlap between the substrate and LDH phase, it was impossible to accurately identify all diffraction peaks derived from the LDH phase and thus its preferred orientation. Nevertheless, cross-sectional SEM image of the LDH network (Fig. 2b) indicated that most of the LDH crystallites should be vertically aligned on the
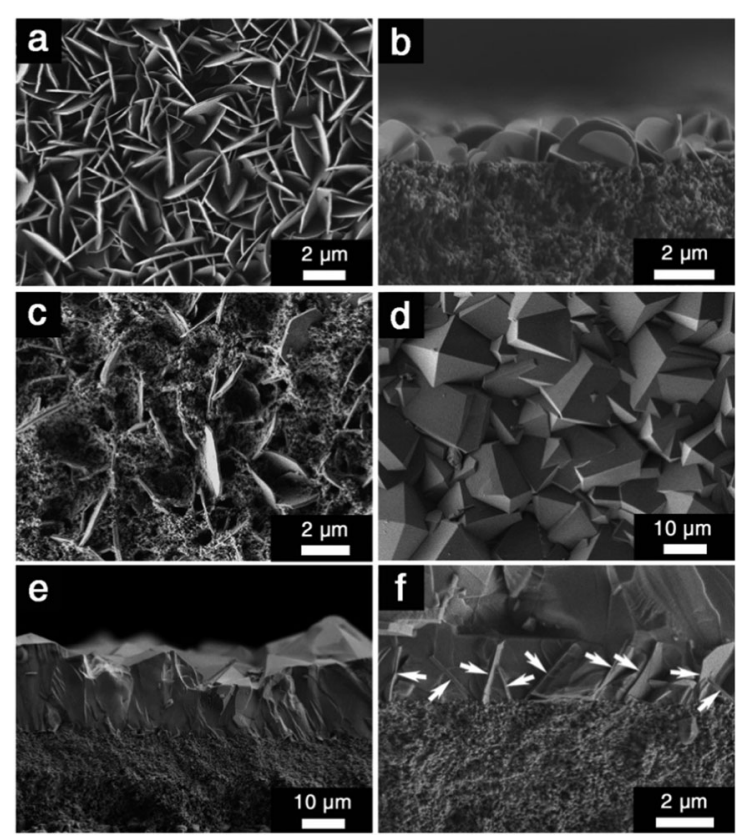

Fig. 2 SEM images of ( $a, b)$ LDH network in situ grown on bare alumina substrate, (c) LDH-modified substrate dip-coated with ZIF- 8 seeds, (d) the top view and $(e, f)$ cross-sectional view of the ZIF- 8 membrane. White arrows: LDH crystallites at the interface between substrate and ZIF- 8 layer.

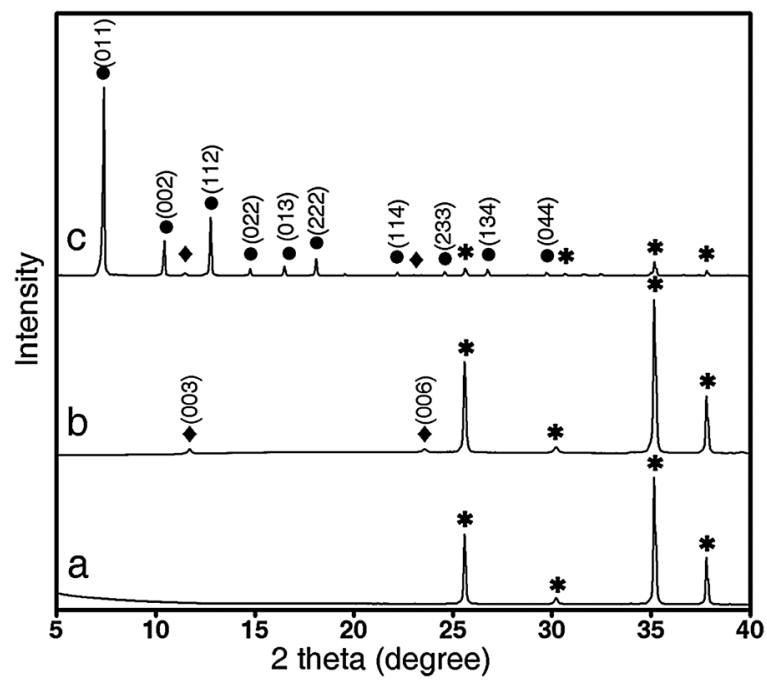

Fig. 3 XRD patterns of (a) bare $\alpha-\mathrm{Al}_{2} \mathrm{O}_{3}$ substrate, (b) $\mathrm{LDH}$ networkmodified $\alpha-\mathrm{Al}_{2} \mathrm{O}_{3}$ substrate and (c) ZIF-8-LDH composite membrane. Peaks marked with dots, rhombuses and asterisks represent diffraction peaks from ZIF-8 layer, LDH network and substrate, respectively.

substrate, which could be interpreted by the "evolution selection" growth mechanism developed by van der Drift in interpretation of the preferred orientation of a vapor-deposited $\mathrm{PbO}$ layer. ${ }^{17}$ For anisotropic $\mathrm{LDH}$ crystals, in the early stage, the $\mathrm{LDH}$ nuclei evolved along all possible crystallographic axes. However, since the growth rate along the $a b$-direction (the largest face of LDHs) was much faster than that along the $c$-direction (the thickness of LDHs), when two LDH crystallites met, the more steeply growing crystal would prevent the further growth of the less steeply growing crystal. Eventually, the largest faces of LDH crystallites tended to arrange in a direction perpendicular to the substrate. The following dip-coating step led to a uniform embedment of ZIF-8 seeds $(\sim 50 \mathrm{~nm} \text { in size, ESI- } 3 \dagger)^{18}$ in LDH lattices (Fig. 2c). After secondary growth, a compact and well-intergrown ZIF-8 membrane with a thickness around $12 \mu \mathrm{m}$ was formed (shown in Fig. $2 \mathrm{~d}$ and e). XRD results showed that new emerging diffraction peaks matched well with the standard diffraction pattern of ZIF-8 powders ${ }^{19}$ (ESI-3 $\dagger$ ) so that the formed layer indeed belonged to ZIF-8 phase. Moreover, the membrane displayed a strong intensity of the (011) reflection in relation to other reflections, thus indicating a preferred crystal orientation of the (011) planes parallel to the support. It was also observed from the magnified cross-sectional image of the ZIF-8 layer (Fig. 2f) that LDH crystallites were not only clearly visible, but also merged well with the ZIF-8 phase. Energydispersive X-ray spectroscopy (EDXS) further proved that the MgAl$\mathrm{CO}_{3} \mathrm{LDH}$ phase was indeed located at the interface of the ZIF-8 layer and $\alpha-\mathrm{Al}_{2} \mathrm{O}_{3}$ substrate (ESI- $4 \dagger$ ).

To evaluate the new composite material as a gas separation membrane, the volumetric flow rates of single and mixed gases through the ZIF-8-LDH composite membrane was measured (ESI-5 $\dagger$ ). As shown in Fig. 4, the prepared ZIF-8 membrane showed a clear molecular sieve effect. The separation factor (SF) of $\mathrm{H}_{2}-\mathrm{CO}_{2}$, $\mathrm{H}_{2}-\mathrm{N}_{2}$ and $\mathrm{H}_{2}-\mathrm{CH}_{4}$ gas pairs reached 4.0, 9.4 and 12.9 with a $\mathrm{H}_{2}$ permeance of $1.4 \times 10^{-7} \mathrm{~mol} \mathrm{~m}^{-2} \mathrm{~s}^{-1} \mathrm{~Pa}^{-1}$. In general the $\mathrm{H}_{2}$ selectivity of this membrane could compete with other high quality ZIF-8 membranes, ${ }^{6,11 c, 20}$ although the $\mathrm{H}_{2}$ permeance was lower than 


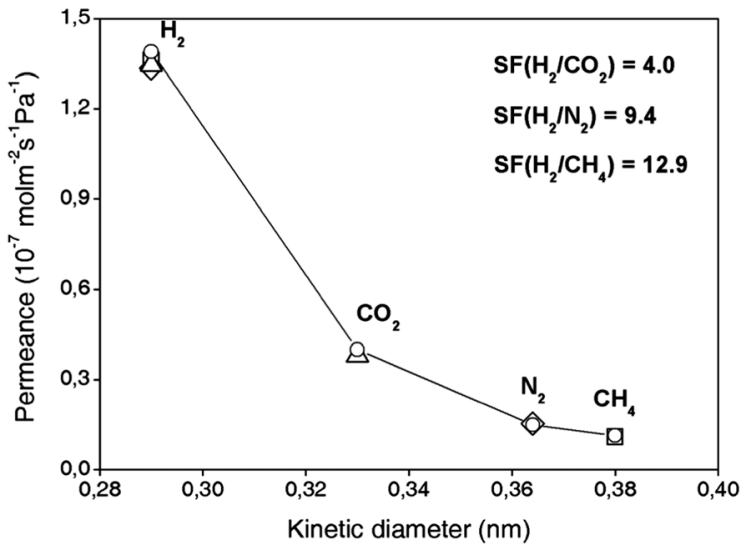

Fig. 4 Permeances of single gases $(\mathrm{O})$ and mixed components of mixtures of $\mathrm{H}_{2}-\mathrm{CO}_{2}(\triangle), \mathrm{H}_{2}-\mathrm{N}_{2}(\diamond)$ and $\mathrm{H}_{2}-\mathrm{CH}_{4}(\square)$ on the prepared ZIF-8 membrane at $\Delta P=1$ bar and $T=25{ }^{\circ} \mathrm{C}$ as a function of molecular kinetic diameters.

some thin $(\sim 2 \mu \mathrm{m})^{21}$ or hollow-fibre supported ZIF-8 membranes. ${ }^{22,23}$ Moreover, to the best of our knowledge, the $\mathrm{H}_{2}-\mathrm{CH}_{4}$ selectivity of our ZIF-8 membrane (12.9) was in general higher than or at least comparable with most reported MOF membranes except $\mathrm{NH}_{2}-\mathrm{MIL}-52$ $(20.7)^{24}$ and APTES-modified ZIF-90 membranes $(71.0)^{25}$ due to a relatively smaller pore size $(0.34 \mathrm{~nm})$. Owing to the framework flexibility of ZIF-8 phase, molecules with a kinetic diameter larger than the pore size of ZIF- 8 such as $\mathrm{CH}_{4}(0.38 \mathrm{~nm})$ could also pass through the membrane. ${ }^{26}$ In summary, the LDH layer had a positive influence on the gas separation performance of the prepared ZIF-8 membrane, deserving further exploration.

For comparison, a pure asymmetric ZIF-8 membrane was also synthesized on a bare $\alpha-\mathrm{Al}_{2} \mathrm{O}_{3}$ substrate without $\mathrm{LDH}$ network by secondary growth under identical conditions (details are shown in ESI-6†). After secondary growth, it was observed that ZIF-8 crystals were only sparsely distributed on the substrate (Fig. S6, ESI $\dagger$ ). This was because ZIF- 8 seeds were only loosely deposited on the bare $\alpha-\mathrm{Al}_{2} \mathrm{O}_{3}$ substrate without any external protection. Due to the weak affinity between the seed layer and substrate, ZIF-8 seeds were prone to detachment from the substrate. This comparative experiment vividly demonstrated the important role of the $\mathrm{LDH}$ network in promoting the attachment of ZIF-8 seeds on the substrate, although in some cases sufficient attachment of MOF seeds on the substrate was not a pre-requisite for high quality MOF membrane preparation. ${ }^{23}$

Our approach was not only limited to ZIF-8 membrane synthesis. For instance, a well-intergrown ZIF-90 membrane could also be prepared (ESI-7 $\dagger$ ) in this way. Similarly, ZIF-90 crystals only sparsely grew on a bare $\alpha-\mathrm{Al}_{2} \mathrm{O}_{3}$ substrate even though the substrate had been pre-coated with a ZIF-90 seed layer before secondary growth (ESI-8 $\dagger$ ).

In conclusion, relying on physical interactions, here we developed a novel seeding method to prepare a novel composite ZIF-8 membrane on porous $\alpha-\mathrm{Al}_{2} \mathrm{O}_{3}$ substrate. The most critical step was to construct a network of crystallographically vertically aligned $\mathrm{LDH}$ walls on the porous $\alpha-\mathrm{Al}_{2} \mathrm{O}_{3}$ substrate. The LDH network effectively collected seeds in a "perch" and prevented ZIF-8 seeds from peeling off during secondary growth. Our ZIF-8 membrane showed considerable $\mathrm{H}_{2}$ selectivity and $\mathrm{H}_{2}$ permeance. This method was not only limited to ZIF-8 membrane synthesis but also could be extended to other MOF membranes such as ZIF-90.
Yi Liu is grateful for the financial support from the Alexander von Humboldt Foundation. We gratefully acknowledge financial support by EU CARENA (FP7-NMP-2010-LARGE-4, Nr. 263007).

\section{Notes and references}

1 (a) B. F. Hoskins and R. Robson, J. Am. Chem. Soc., 1990, 112, 1546; (b) M. Kondo, T. Yoshitomi, K. Seki, H. Matsuzaka and S. Kitagawa, Angew. Chem., Int. Ed. Engl., 1997, 36, 1725; (c) M. Fujita, Y. J. Kwon, S. Washizu and K. Ogura, J. Am. Chem. Soc., 1994, 116, 1151; (d) O. M. Yaghi and H. L. Li, J. Am. Chem. Soc., 1995, 117, 10401; (e) D. Venkataraman, G. B. Gardner, S. Lee and J. S. Moore, J. Am. Chem. Soc., 1995, 117, 11600.

2 (a) H. L. Li, M. Eddaoudi, M. O'Keeffe and O. M. Yaghi, Nature, 1999, 402, 276; (b) M. Deshmukh, M. Ohba, S. Kitagawa and S. Sakaki, J. Am. Chem. Soc., 2013, 135, 4840.

3 (a) D. Zacher, O. Shekhah, C. Wöll and R. A. Fischer, Chem. Soc. Rev., 2009, 38, 1418; (b) O. Shekhah, J. Liu, R. A. Fischer and C. Wöll, Chem. Soc. Rev., 2011, 40, 1081; (c) M. Shah, M. C. McCarthy, S. Sachdeva, A. K. Lee and H. K. Jeong, Ind. Eng. Chem. Res., 2012, 51, 2179; (d) J. Gascon, F. Kapteijn, B. Zornoza, V. Sebastian, C. Casado and J. Coronas, Chem. Mater., 2012, 24, 2829.

4 (a) Y. Yoo, Z. P. Lai and H. K. Jeong, Microporous Mesoporous Mater., 2009, 123, 100; (b) Y. Y. Liu, Z. F. Ng, E. A. Khan, H. K. Jeong, C. B. Ching and Z. P. Lai, Microporous Mesoporous Mater., 2009, 118, 296; (c) H. Bux, F. Y. Liang, Y. S. Li, J. Cravillon, M. Wiebcke and J. Caro, J. Am. Chem. Soc., 2009, 131, 16000; (d) H. Guo, G. Zhu, I. J. Hewitt and S. Qiu, J. Am. Chem. Soc., 2009, 131, 1646.

5 A. Huang, H. Bux, F. Steinbach and J. Caro, Angew. Chem., Int. Ed., 2010, 49, 4958.

6 M. C. McCarthy, V. V. Guerrero, G. Barnett and H. K. Jeong, Langmuir, 2010, 26, 14636.

7 Y. Yoo and H. K. Jeong, Chem. Commun., 2008, 2441.

8 I. Stassen, N. Campagnol, J. Fransaer, P. Vereecken, D. De Vos and R. Ameloot, CrystEngComm, 2013, 15, 9308.

9 (a) R. Ranjan and M. Tsapatsis, Chem. Mater., 2009, 21, 4920; (b) Y. S. Li, F. Y. Liang, H. Bux, A. Feldhoff, W. S. Yang and J. Caro, Angew. Chem., Int. Ed., 2010, 49, 548; (c) Y. S. Li, F. Y. Liang, H. Bux, W. S. Yang and J. Caro, J. Membr. Sci., 2010, 354, 48.

10 (a) V. V. Guerrero, Y. Yoo, M. C. McCarthy and H. K. Jeong, J. Mater. Chem., 2010, 20, 3938; (b) E. V. Ramos-Fernandez, M. Garcia-Domingos, J. Juan-Alcaniz, J. Gascon and F. Kapteijn, Appl. Catal., A, 2011, 391, 261.

11 (a) Y. Hu, X. Dong, J. Nan, W. Jin, X. Ren, N. Xu and Y. M. Lee, Chem. Commun., 2011, 47, 737; (b) X. L. Dong and Y. S. Lin, Chem. Commun., 2013, 49, 1196; (c) X. F. Zhang, Y. Q. Liu, L. Y. Kong, H. O. Liu, J. S. Qiu, W. Han, L. T. Weng, K. L. Yeung and W. D. Zhu, J. Mater. Chem. A, 2013, 1, 10635; (d) Y. Yoo, Z. P. Lai and H. K. Jeong, Microporous Mesoporous Mater., 2009, 123, 100.

12 R. Ameloot, F. Vermoortele, W. Vanhove, M. B. J. Roeffaers, B. F. Sels and D. E. De Vos, Nat. Chem., 2011, 3, 382.

13 J. Yao, D. Dong, D. Li, L. He, G. Xu and H. Wang, Chem. Commun., 2011, 47, 2559.

14 H. T. Kwon and H. K. Jeong, J. Am. Chem. Soc., 2013, 135, 10763.

15 Q. Wang and D. O'Hare, Chem. Rev., 2012, 112, 4124.

16 H. Y. Chen, F. Z. Zhang, T. Chen, S. L. Xu, D. G. Evans and X. Duan, Chem. Eng. Sci., 2009, 64, 2617.

17 A. van der Drift, Philips Res. Rep., 1967, 22, 267.

18 J. Cravillon, S. Munzer, S. J. Lohmeier, A. Feldhoff, K. Huber and M. Wiebcke, Chem. Mater., 2009, 21, 1410.

19 J. Cravillon, C. A. Schröder, H. Bux, A. Rothkrich, J. Caro and M. Wiebcke, CrystEngComm, 2012, 14, 492.

20 H. Bux, A. Feldhoff, J. Cravillon, M. Wiebcke, Y. S. Li and J. Caro, Chem. Mater., 2011, 23, 2262.

21 D. F. Liu, X. L. Ma, H. X. Xi and Y. S. Lin, J. Membr. Sci., 2014, 451, 85.

22 K. Tao, L. J. Cao, Y. C. Lin, C. L. Kong and L. Chen, J. Mater. Chem. A, 2013, 1, 13046.

23 Y. Pan, B. Wang and Z. Lai, J. Membr. Sci., 2012, 421-422, 292.

24 F. Zhang, X. Q. Zou, X. Gao, S. J. Fan, F. X. Sun, H. Ren and G. S. Zhu, Adv. Funct. Mater., 2012, 22, 3583.

25 A. S. Huang, N. Y. Wang, C. L. Kong and J. Caro, Angew. Chem., Int. Ed., 2012, 51, 10551.

26 D. Fairen-Jimenez, S. A. Moggach, M. T. Wharmby, P. A. Wright, S. Parsons and T. Düren, J. Am. Chem. Soc., 2011, 133, 8900. 